\title{
The Associations between Interleukin-17 Single Nucleotide Polymorphism and Colorectal Cancer Susceptibility: A Systematic Review and Meta-Analysis
}

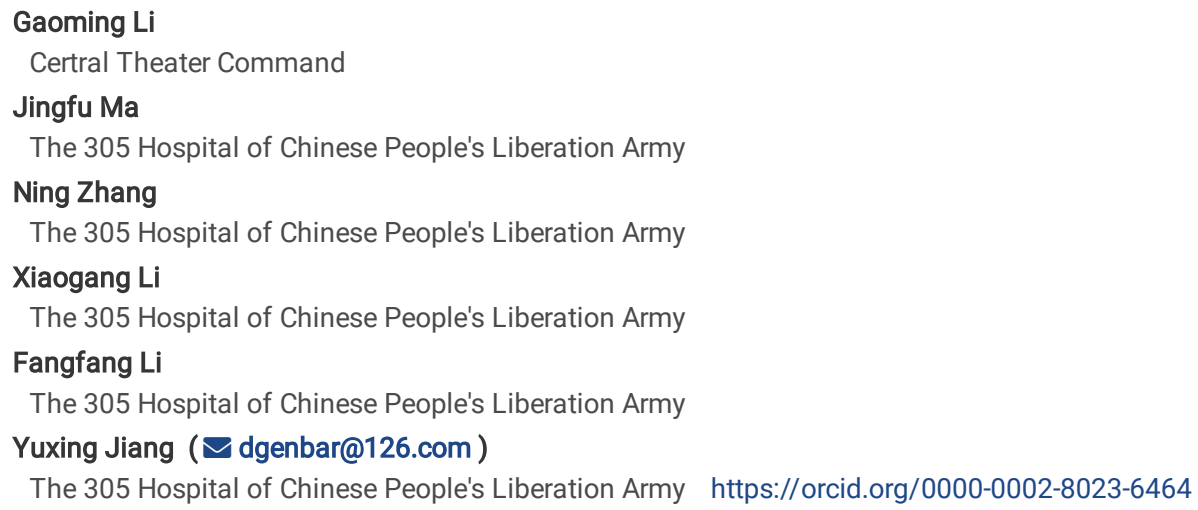

Version of Record: A version of this preprint was published at World Journal of Surgical Oncology on April 12th, 2022. See the published version at https://doi.org/10.1186/s12957-022-02586-2. 


\begin{abstract}
Backgrounds: Numerous of case-control studies have reported the associations between Interleukin-17 (IL-17) polymorphisms and colorectal cancer, however, the results were inconsistent. The aim of this meta-analysis was to further clarify the effects of IL-17 polymorphisms on colorectal cancer susceptibility.
\end{abstract}

Materials and method: Relevant Studies were extracted from electronic databases of Pubmed, Embase, Web of science, China National Knowledge Infrastructure (CNKI) and Chinese Biomedical Literature Database (CMB) up to April 2021. The Odds ratio and 95\% confidence interval were conducted to estimate the strength of the associations and the Stata 13.0 software was used to perform the meta-analysis.

Results: Ten articles including 2599 cases and 2845 controls were enrolled in our research after strictly literature screening. Highly significant associations between IL-17A rs2275913 polymorphism and increased colorectal cancer susceptibility were observed in all the five gene models (allelic, dominant, recessive, homozygous and heterozygous models), subgroup analysis based on ethnicity revealed that these associations existed not only in Asia population, but also in Caucasian population. However, the results showed no significantly elevated colorectal cancer risk correlated to IL-17F rs 763780 polymorphism and a slightly lower colorectal cancer susceptibility for Caucasian population was discovered in the recessive and homozygous models of this mutation.

Conclusion: IL-17A rs2275913 polymorphism may be an independent risk factor contributed to colorectal cancer susceptibility, while IL-17F rs763780 polymorphism displayed a possible decreased susceptibility to colorectal cancer. Future studies with large-scale samples were warranted to identify these associations.

\title{
1. Introduction
}

Epidemiological data from last year showed that colorectal cancer has become the third most common and the second lethal malignant tumor. With a high morbidity and mortality, colorectal cancer caused almost 2 million diagnosed cases and approximately 1 million cancer-related deaths throughout the world per year[1], posing a major threat to the normal lives and providing a heavy global burden of human health[2]. Although the specific mechanism of colorectal cancer tumorigenesis remains uncertain presently, accumulative evidence demonstrated that these factors, such as environment, diet, smoking, alcohol and some precancerous lesions, were closely associated with the occurrence of colorectal cancer[3-5]. However, even if exposed to the same environmental factors, only a small proportion of people suffer from colorectal cancer, which suggested that genetic factors might play a crucial role in the pathogeny of colorectal cancer. Some current studies have indicated that single nucleotide polymorphisms, especially the polymorphisms from inflammatory cytokines, had access to interfere and modify the protein expressions and increased the colorectal malignant tumor susceptibility[6].

The synergy of inflammatory microenvironment and some carcinogenic cytokines was well recognized in the cancer progression[7]. Chronic inflammation was proved to be strongly associated with the genetic instability and related mechanism in cancer inflammatory microenvironment, indicating that gene mutation and inflammation may closely participated in the pathogenesis and progression of malignant tumors[8]. IL-17, also called as IL-17A or CTLA-8, was an inflammatory cytokine secreted by T helper 17 cells. As the named subspecies in the IL-17 gene family, it was firstly discovered from the cDNA of a hybrid rodent T cells[9]. The IL-17 family contained at least six members, which was IL-17A to F, each of them had the similar gene sequences and biological functions[10]. Recently, a number of researches has confirmed the effects of IL-17 on the initiation and development of multiple types of malignancies, including Hepatocellular carcinoma[11], lung cancer[12], pancreatic cancer[13] and cervical cancer[14]. Although IL-17A and IL-17F was clarified as risk factors for colorectal cancer during the recent decade[15], the concrete reasons were unclear.

It is widely reported that IL-17A and IL-17F polymorphic variants were positively correlated with increased susceptibility of some primary malignancies [16-18]. Furthermore, the positive relationships were observed between inflammatory bowel diseases, regarding as the precancerous lesions of colorectal cancer, and IL-17A and IL-17F polymorphisms in several previous literatures[19, 20], and increasing numbers of studies has performed to investigate whether these polymorphisms contribute to colorectal cancer, however, the results were still controversy. Hence, this meta-analysis was conducted to firstly explore the association between IL-17A rs2275913 and IL-17F rs763680 polymorphisms and colorectal cancer.

\section{Materials And Methods}

\subsection{Search strategy of literatures}

An Internet search for the literatures published in English or Chinese was conducted from the establishment date of databases of Pubmed, Web of science, Embase, CNKI and CMB to April 2021, with the following key words: "Interleukin-17 or IL-17 or CTLA-8" and "CRC or colorectal cancer or colon cancer or rectal cancer" and "SNP or polymorphism or single nucleotide polymorphism or gene mutation or gene variant". Relevant conference papers were retrieved using the journal database of National library of China by a manual search.

\subsection{Inclusion and exclusion criteria}

All the eligible studies including in this meta-analysis should meet the criteria as: (1). The studies were set out to investigate the associations between IL-17A rs2275913 or IL-17F rs763780 polymorphisms and colorectal cancer susceptibility. (2). The studies were case-control studies. (3). There were available and adequate genotype frequencies to evaluate the odds ratio $(\mathrm{OR})$ and $95 \%$ confidence interval $(\mathrm{Cl})$. (4). The studies were carried out only on human beings.

The studies with following criteria should be excluded from this meta-analysis: (1). The aims of the studies were not to detect the effect of IL-17A rs2275913 or IL-17F rs763780 polymorphism on colorectal cancer. (2). Non-case-control studies. (3). Duplicated publications or studies with overlapping data. (4). The studies without extractable data of genotype frequencies. (5). The publications identified to be review, case-reports, letter to editors and brief communications. 
Available data were extracted by two independent investigators from the enrolled articles, including study author, study year, study design, ethnicity of population, source of controls, genotyping methods, Matching criteria of cases and controls, genotype frequencies and the calculated Hardy-Weinberg equilibrium (HWE). For repeated publications, only the researches with the largest sample size and highest quality or the most exhaustive information was selected. If any disagreement appeared, a third investigator may involve in the discussion until the final agreement reached.

\subsection{Quality score assessment}

The quality of each enrolled literatures was assessed by the developed standard consisting of 6 aspects of representativeness of cases, source of controls, case-control matching, specimens used for determining genotypes, HWE, and total sample size as previously reported $\mathbb{T}$ Table 1区[21]. The total score ranged from 0 to 18 and score for each aspects ranged from 0 to 3 , literatures with a total score $\geq 12$ was considered high quality, otherwise, literatures with a total score $₫ 12$ was considered low quality.

\subsection{Statistic analysis}

All statistical tests in this study were bilateral, and the difference with $P<0.05$ was considered statistically significant unless otherwise stated. The association of mutation sites with colorectal cancer risk was assessed by odds ratio OR and its corresponding $95 \%$ confidence interval $\mathrm{Cl}$, and the $\mathrm{Z}$ test was used for the statistical significance test of combined OR value. $\chi^{2}$ test was used to test whether the genotypes of the control group met HWE. The Cochrane Q test was used to detect whether heterogeneity existed among the studies and its statistical quantity $Q$ approximately followed the $\chi^{2}$ distribution with k-1 degree of freedom ( $k$ was the number of studies), $P$ value less than 0.10 suggested that heterogeneity existed among studies. At the same time, the heterogeneity was quantitatively evaluated by combining the $R$ value. The $R$ value ranged from 0 to $100 \%$ and the larger the value, the higher the heterogeneity. In general, $R$ less than $25 \%$ indicated mild heterogeneity, $R$ between $25 \%$ and $50 \%$ indicated moderate heterogeneity and $R$ more than $50 \%$ indicates high heterogeneity. When the heterogeneity test in various studies was $P<0.10$ or $P>50 \%$, the random effect model (DerSimonian-Laird method) was employed for Meta-analysis, otherwise, the fixed effect model (Mantel-Haenszel method) was employed. Sensitivity analysis was performed to determine the stability of conclusions by removing the enrolled studies one by one and estimated whether the results changed. The funnel plots drawn by effect size and standard error was carried out to evaluated possible publication bias and Begg's rank correlation was used to test the asymmetry of the funnel plots. All the statistical analysis was calculated using the software of Stata version 13.0 (STATA Corporation, College Station, TX, USA).

\section{Results}

\subsection{Characteristics of publications}

Totally, 1353 related articles were obtained in the preliminary examination, and the remaining 619 articles were excluded from repeated articles. According to the inclusion and exclusion criteria, the preliminary screening for articles was conducted by reading titles and abstracts, and 426 articles unrelated to the research topic were excluded. After then further reading the full text, 298 articles were excluded, including 193 researches unrelated to colorectal cancer, 71 abstracts or systematic reviews, 27 non-case control or cohort studies, 4 prognosis studies of colorectal cancer, 2 without complete genotype frequency or data available data and 1 with duplicated data. Finally, 14 case-control studies including 2599 cases and 2845 controls from 10 papers meeting the inclusion criteria were selected for this meta-analysis[22-31] هFigure 1ه. Among included studies, 8 were conducted for IL-17A rs2275913 polymorphism and 6 were conducted for IL-17F rs763780 polymorphism, 6 were regarding to Asian and 8 were regarding to Caucasian. A total of 9 studies were considered high-quality ( $\geq 12$ ) via quality score assessment. The basic characteristics of each included study were summarized in Table 2.

\subsection{Associations between IL-17A rs2275913 polymorphism and colorectal cancer}

Overall analysis revealed that all the five genetic models (allelic, dominant, recessive, homozygous and heterozygous models) of IL-17A rs2275913 polymorphism were related with an elevated colorectal cancer risk (A vs. G: OR $=1.59,95 \% \mathrm{Cl}=1.34-1.89, P<0.001 ; \mathrm{AA} / \mathrm{AG}$ vs. GG: OR $=1.75,95 \% \mathrm{Cl}=1.36-$ $2.25, P<0.001 ; \mathrm{AA}$ vs. GG/AG: $\mathrm{OR}=1.74,95 \% \mathrm{Cl}=1.41-2.15, P<0.001 ; \mathrm{AA}$ vs. $\mathrm{GG}: \mathrm{OR}=2.05,95 \% \mathrm{Cl}=1.62-2.60, P<0.001 ; \mathrm{AG}$ vs. $\mathrm{GG}: \mathrm{OR}=1.60,95 \% \mathrm{Cl}=$ 1.23-2.09, $P=0.001$ )(Table 3). when subgroup analysis was performed according to ethnicity, the higher risk of colorectal cancer was observed not only in Asian population (A vs. G: $\mathrm{OR}=1.52,95 \% \mathrm{Cl}=1.16-2.01, P=0.003 ; \mathrm{AA} / \mathrm{AG}$ vs. GG: $\mathrm{OR}=1.62,95 \% \mathrm{Cl}=1.18-2.23 P=0.003 ; \mathrm{AA}$ vs. GG/AG: OR $=1.72,95 \% \mathrm{Cl}$ $=1.26-2.34, P=0.001$; AA vs. GG: $\mathrm{OR}=2.10,95 \% \mathrm{Cl}=1.49-2.96, P<0.001 ; \mathrm{AG}$ vs. $\mathrm{GG}: \mathrm{OR}=1.43,95 \% \mathrm{Cl}=1.14-1.80, P=0.002)$, but also in Caucasian population (A vs. G: $\mathrm{OR}=1.67,95 \% \mathrm{Cl}=1.30-2.14, P<0.001 ; \mathrm{AA} / \mathrm{AG}$ vs. $\mathrm{GG}: \mathrm{OR}=1.88,95 \% \mathrm{Cl}=1.26-2.81 P=0.002 ; \mathrm{AA}$ vs. $\mathrm{GG} / \mathrm{AG}: \mathrm{OR}=1.76,95 \% \mathrm{Cl}=$ 1.32-2.36, $P<0.001$; AA vs. GG: $\mathrm{OR}=2.01,95 \% \mathrm{Cl}=1.46-2.77, P<0.001$; $\mathrm{AG}$ vs. $\mathrm{GG}$ : $\mathrm{OR}=1.76,95 \% \mathrm{Cl}=1.11-2.80, P=0.017)($ Figure $2 \mathrm{~A}-\mathrm{E})$. The result from stratified analysis classified by the source of controls exhibited a significant colorectal cancer susceptibility correlated to IL-17A rs2275913 polymorphism in population-based (PB) (A vs. G: OR = 1.47, 95\% Cl=1.25-1.72, $P<0.001 ; \mathrm{AA} / \mathrm{AG}$ vs. $\mathrm{GG}$ : $\mathrm{OR}=1.50,95 \% \mathrm{Cl}=1.23-1.83, P<0.001 ; \mathrm{AA}$ vs. $\mathrm{GG} / \mathrm{AG}$ : OR $=1.74$, $95 \% \mathrm{Cl}=1.39-2.18, P<0.001$; AA vs. GG: OR $=1.96,95 \% \mathrm{Cl}=1.53-2.50, P<0.001$; AG vs. GG: $\mathrm{OR}=1.35,95 \% \mathrm{Cl}=1.11-1.65, P=0.003)$ and in hospital-based (HB) controls (A vs. G: OR $=2.15,95 \% \mathrm{Cl}=1.41-3.29, P<0.001 ; \mathrm{AA} / \mathrm{AG}$ vs. GG: $\mathrm{OR}=3.15,95 \% \mathrm{Cl}=1.59-6.21, P=0.001 ; \mathrm{AA}$ vs. GG: OR=3.20, 95\% $\mathrm{Cl}=1.52-$ 6.76, $P=0.002 ; \mathrm{AG}$ vs. GG: $\mathrm{OR}=2.95,95 \% \mathrm{Cl}=1.82-4.79, P<0.001)$ except for the recessive models.

\subsection{Associations between IL-17F rs763780 polymorphism and colorectal cancer}

No significant associations between IL-17F rs763780 polymorphism and colorectal cancer were detected in the overall analysis (Table 3). We also failed to found any correlations in the further subgroup analyses based on source of controls and genotyping methods. Interestingly, when stratified analysis was classified by ethnicity (Figure 3A-E), we discovered a decreased colorectal cancer risk for the Caucasian population in the recessive model (CC vs. CT/TT: OR = $0.54,95 \% \mathrm{Cl}=0.30-0.98, P=0.042)$ and homozygous model (CC vs.TT: OR $=0.43,95 \% \mathrm{Cl}=0.21-0.87, P=0.019)$. 


\subsection{Sensitive analysis and cumulative meta-analysis}

The destination of sensitive analysis was to detect whether the pooled OR results could be affected by any single enrolled study, we found no significant alteration exist in the pooled OR for IL-17A rs2275913 and IL-17F rs763780 polymorphisms when any one study was eliminated from this meta-analysis, indicating the reliability of our results. The cumulative analysis was performed on the basis of the publication year of literatures and the result showed that with the number of studies increased, the combined effect sizes and confidence intervals trended to be stable.

\subsection{Publication bias}

For the assessment of publication bias, the Begg's funnel plot and Egge's test were conducted (Figure 4 and Figure 5). The results for IL-17A rs2275913 polymorphism displayed a certain publication bias in the allelic model $(P=0.001)$ (Figure 4A) and dominant model ( $P=0.001)$ (Figure 4B), a slight publication bias was observed in the heterozygous model $(P=0.021)$ (Figure $4 \mathrm{E}$ ). Regarding to IL-17F rs763780 polymorphism, the funnel plots for all the models were symmetrical and suggested the absence of significant publication bias (Figure $5 \mathrm{~A}-\mathrm{E}$ ).

\section{Discussion}

Growing evidence revealed positive influence of inflammatory cytokine IL-17 on the colorectal cancer development, leading a poor prognosis for the patients. Further studies explicitly determined IL-17 involved in the colorectal cancer cells proliferation[32], migration and invasion[33], angiogenesis[34] and enhanced drug resistance $[35,36]$ by regulating a series of downstream signaling pathways, significantly improving the tumorigenesis, invasive and distant metastasis capabilities of colorectal cancer. The role of IL-17 in the occurrence of colorectal cancer has also received more and more attention.

Among the six members of IL-17 family, IL-17F shared the highest similar amino acid sequence and overlapping functions with IL-17A[37]. Each of the two genes was consisted of 3 exons and 2 introns and located on the chromosome 6p12.3-q13. The genetic variant of IL-17A rs2275913 was located in the 5'UTR, involving in the gene transcription regulations and changing the roles of some cytokines[38], IL-17F rs763780 polymorphism was identified to be a missense mutation located on the coding region, with the amino acid modifying conversion of His to Arg, resulting in the potential changing of protein expressions and possible cancer risk[25]. An increasing number of studies and meta-analysis were performed to explore associations between the IL-17A rs2275913 and IL-17F rs763780 polymorphisms and virous kinds of malignant tumors in recent years[39-41], however, the related findings for colorectal cancer displayed no consensus. Thus, this meta-analysis was to detect whether both the two polymorphisms contribute to colorectal cancer susceptibility

Our present research was comprised of 2599 cases and 2845 controls from the selected 10 case-control studies, the overall analysis results revealed a highly significantly positive associations between IL-17A rs2275913 polymorphism and colorectal cancer in all the five genetic models (A vs. G, AA/AG vs. GG, AA vs. $A G / G G, A A$ vs. $G G$ and $A G$ vs. GG), suggesting that this mutation may be a remarkable genetic risk factor in the tumorigenesis of colorectal cancer. However, when the analysis was performed in IL-17F rs763780 polymorphism, no associations for colorectal cancer were observed in any genetic models (C vs. T, CC/CT vs. TT, CC vs. CT /TT, CC vs. TT and CT vs. TT). The combined effect size did not change significantly when the enrolled studies were excluded one by one, ensuring the reliability of these associations. Besides, it was noteworthy that heterogeneities existed in statistical results for some genetic models.

To explore the origin of heterogeneities and further explain the impact of different factors on the contributions of IL-17A rs2275913 and IL-17F rs763780 polymorphisms to colorectal cancer susceptibility, a series of subgroup analysis based on the aspects of race, source of controls and genotyping method were conducted. The results of analysis classified by ethnicity displayed an increased colorectal cancer risk from IL-17A rs2275913 polymorphism in both Asian and Caucasian subgroups, revealing that this mutation might independently rise the susceptibility to colorectal cancer risk in Asian and Caucasian populations. However, for the IL-17F rs763780 polymorphism, a decreased risk correlated with colorectal cancer in Caucasian subgroup was observed in the recessive and homozygous models, which suggested that the biological functions of IL-17F rs763780 polymorphism for populations from various races was possibly discrepant and provided a negative predictor for colorectal cancer occurrence in Caucasians, however, the insufficient sample size advised that such result was necessary to be identified by further studies. When stratified analysis was performed in terms of the source of controls, we found that only the HB population in the recessive model of IL-17A rs2275913 polymorphism showed no significant relationship with elevated colorectal cancer risk, since these cases were underwent the influence of self-underlying diseases, radioactive examinations and drug treatment during the hospitalization, such factors had access to potentially affect the results of genetic assessment[42]. In the models from IL-17F rs763780 polymorphism, no significant association with colorectal cancer susceptibility was observed in either PB or HB populations. We further discovered some statistical discrepancies among the subgroups divided by genotyping methods for IL-17A rs2275913 polymorphism, which indicated that various detection methods may also impact genotyping results.

Despite this meta-analysis was performed with rigorous design and exact calculations, several inevitable limitations should be noted. Firstly, some heterogeneities were observed in the overall analyses for both the two polymorphism, stratified analyses classified by ethnic, source of controls and some other subgroups failed to completely eliminate these heterogeneities. Secondly, the data of age, sex, living styles and exposures to smoking or drinking were unable to be further extracted, such factors may also impact the occurrence and development of cancer, available information of these unadjusted estimates was essential for a more accurate analysis. Thirdly, all the selected studies were conducted in the races of Asian and Caucasian and the geography areas were limited to East Asia, West Asia and North Africa, therefore, the studies with related data from some other races and geography areas were required to verify these findings. Fourthly, all the included literatures were published in English and Chinese, papers written in other languages and unpublished data due to negative results were not obtained, which may responsible for the publication bias detected in IL-17A rs2275913 polymorphism, future analysis with more enrolled studies probably overcome this issue. Moreover, the sample size of this meta-analysis was relatively small and the findings need to be discussed in further researches with large samples.

In conclusion, this meta-analysis displayed a significant association between IL-17A rs2275913 polymorphism and susceptibility to colorectal cancer among Asians and Caucasians, which provided a potential risk factor of colorectal cancer for the two populations. Although we failed to discovered no positive 
effects of IL-17F rs763780 polymorphism on the colorectal cancer occurrence, this mutation may have access to decrease the colorectal cancer risk in Caucasians. The analysis results showed in our present research were warranted to be identified by continued well-designed and high-level studies, especially some prospective studies in the future.

\section{Abbreviations}

IL-17, interleukin-17

CBM, Chinese Biomedical Literature Database

CNKI, China National Knowledge Infrastructure

$\mathrm{OR}$, odds ratio

$\mathrm{Cl}$, confidence interval

HWE, Hardy

Weinberg genetic equilibrium law

PB, population-based

HB, hospital-based.

\section{Declarations}

\section{Ethics approval and consent to participate}

Our analysis is based on previously published data, so the ethical approval may be not concerned.

\section{Consent for publication}

Not applicable

\section{Availability of data and materials}

The datasets used and/or analysed during the current study are available from the corresponding author on reasonable request

\section{Competing interests}

The authors declare that they have no competing interests

\section{Funding}

This project was supported by grants from the National Natural Science Foundation of China (81372559)

\section{Authors' contributions}

Study concept and design, interpretation of data and critical revision: GL and YJ. Literatures review and data analysis: $G L, N Z, X L$ and FL. Drafting of the manuscript: GL and YJ. Revision of the manuscript: YJ. Obtained funding: JM and YJ. All authors read and approved the final manuscript.

\section{Acknowledgements}

Not applicable

\section{References}

1. Sung H, Ferlay J, Siegel RL, Laversanne M, Soerjomataram I, Jemal A, Bray F: Global Cancer Statistics 2020: GLOBOCAN Estimates of Incidence and Mortality Worldwide for 36 Cancers in 185 Countries.CA Cancer J Clin 2021, 71:209-249.

2. Ladabaum U, Dominitz JA, Kahi C, Schoen RE: Strategies for Colorectal Cancer Screening.Gastroenterology 2020, 158:418-432.

3. Song M, Chan AT: Environmental Factors, Gut Microbiota, and Colorectal Cancer Prevention.Clin Gastroenterol Hepatol 2019 , 17:275-289.

4. Hansen RD, Sorensen M, Tjonneland A, Overvad K, Wallin H, Raaschou-Nielsen O, Vogel U: XPA A23G, XPC Lys939GIn, XPD Lys751Gln and XPD Asp312Asn polymorphisms, interactions with smoking, alcohol and dietary factors, and risk of colorectal cancer.Mutat Res 2007, 619:68-80.

5. Conteduca V, Sansonno D, Russi S, Dammacco F: Precancerous colorectal lesions (Review).Int J Oncol 2013, 43:973-984.

6. Liu L, Zhai Z, Wang D, Ding Y, Chen X, Wang Q, Shu Z, Wu M, Chen L, He X, et al: The association between IL-1 family gene polymorphisms and colorectal cancer: A meta-analysis.Gene 2021, 769:145187.

7. Trivedi S, Rosen CA, Ferris RL: Current understanding of the tumor microenvironment of laryngeal dysplasia and progression to invasive cancer.Curr Opin Otolaryngol Head Neck Surg 2016, 24:121-127.

8. Kawanishi S, Ohnishi S, Ma N, Hiraku Y, Murata M: Crosstalk between DNA Damage and Inflammation in the Multiple Steps of Carcinogenesis.Int J Mol Sci 2017, 18.

9. Singh RK, Lee KM, Vujkovic-Cvijin I, Ucmak D, Farahnik B, Abrouk M, Nakamura M, Zhu TH, Bhutani T, Wei M, Liao W: The role of IL-17 in vitiligo: A review.Autoimmun Rev 2016, 15:397-404. 
10. McGeachy MJ, Cua DJ, Gaffen SL: The IL-17 Family of Cytokines in Health and Disease.Immunity 2019, 50:892-906.

11. Zarogoulidis P, Katsikogianni F, Tsiouda T, Sakkas A, Katsikogiannis N, Zarogoulidis K: Interleukin-8 and interleukin-17 for cancer.Cancer Invest 2014 , 32:197-205.

12. Wu F, Xu J, Huang Q, Han J, Duan L, Fan J, Lv Z, Guo M, Hu G, Chen L, et al: The Role of Interleukin-17 in Lung Cancer.Mediators Inflamm 2016, 2016:8494079.

13. Hu F, Guo F, Zhu Y, Zhou Q, Li T, Xiang H, Shang D: IL-17 in pancreatic disease: pathogenesis and pharmacotherapy.Am J Cancer Res 2020, 10:3551-3564.

14. Alves JJP, De Medeiros Fernandes TAA, De Araujo JMG, Cobucci RNO, Lanza DCF, Bezerra FL, Andrade VS, Fernandes JV: Th17 response in patients with cervical cancer.Oncol Lett 2018, 16:6215-6227.

15. Razi S, Baradaran Noveiry B, Keshavarz-Fathi M, Rezaei N: IL-17 and colorectal cancer. From carcinogenesis to treatment.Cytokine 2019, 116:7-12.

16. Wang H, Zhang Y, Liu Z, Zhang Y, Zhao H, Du S: The IL-17A G-197A and IL-17F 7488T/C polymorphisms are associated with increased risk of cancer in Asians: a meta-analysis.Drug Des Devel Ther 2015, 9:5159-5168.

17. Aguin N, Rodriguez-Alonso A, Lopez-Trigo N, Castuera IP, Luis JR, Caeiro B: Association Between the Interleukin-17 Gene Polymorphism -197G>A and the Risk of Prostate Cancer in a Galician Population.Pathol Oncol Res 2020, 26:483-489.

18. Chen L, Li XG, Wang JF, Hao RS, Xiang WY, Tan PF, Xia NN, Wang W, Wang ZR, Shen J: Potential effects of IL-17A rs2275913 and IL-17F rs763780 polymorphisms on susceptibility to gastric cancer in Chinese population: a meta-analysis.Eur Rev Med Pharmacol Sci 2020, 24:3633-3641.

19. Chen B, Zeng Z, Hou J, Chen M, Gao X, Hu P: Association of interleukin-17F 7488 single nucleotide polymorphism and inflammatory bowel disease in the Chinese population.Scand J Gastroenterol 2009, 44:720-726.

20. Kim SW, Kim ES, Moon CM, Park JJ, Kim TI, Kim WH, Cheon JH: Genetic polymorphisms of IL-23R and IL-17A and novel insights into their associations with inflammatory bowel disease.Gut 2011, 60:1527-1536.

21. Thakkinstian A, McEvoy M, Minelli C, Gibson P, Hancox B, Duffy D, Thompson J, Hall I, Kaufman J, Leung TF, et al: Systematic review and meta-analysis of the association between \{beta\}2-adrenoceptor polymorphisms and asthma: a HuGE review.Am J Epidemiol 2005, 162:201-211.

22. Samiei G, Yip WK, Leong PP, Jabar MF, Dusa NM, Mohtarrudin N, Seow HF: Association between polymorphisms of interleukin-17A G197A and interleukin17F A7488G and risk of colorectal cancer.J Cancer Res Ther 2018, 14:S299-S305.

23. Al Obeed OA, Vaali-Mohamed MA, Alkhayal KA, Bin Traiki TA, Zubaidi AM, Arafah M, Harris RA, Khan Z, Abdulla MH: IL-17 and colorectal cancer risk in the Middle East: gene polymorphisms and expression.Cancer Manag Res 2018, 10:2653-2661.

24. Bedoui SA, Barbirou M, Stayoussef M, Dallel M, Mokrani A, Makni L, Mezlini A, Bouhaouala B, Yacoubi-Loueslati B, Almawi WY: Association of interleukin17A polymorphisms with the risk of colorectal cancer: A case-control study. Cytokine 2018, 110:18-23.

25. Feng H, Ying R, Chai T, Chen H, Ju H: The association between IL-17 gene variants and risk of colorectal cancer in a Chinese population: A case-control study.Biosci Rep 2019, 39

26. Nemati K, Golmoghaddam H, Hosseini SV, Ghaderi A, Doroudchi M: Interleukin-17FT7488 allele is associated with a decreased risk of colorectal cancer and tumor progression. Gene 2015, 561:88-94.

27. Omrane I, Marrakchi R, Baroudi O, Mezlini A, Ayari H, Medimegh I, Stambouli N, Kourda N, Bouzaienne H, Uhrhammer N, et al: Significant association between interleukin-17A polymorphism and colorectal cancer. Tumour Biol 2014, 35:6627-6632.

28. Omrane I, Baroudi O, Bougatef K, Mezlini A, Abidi A, Medimegh I, Stambouli N, Ayari H, Kourda N, Uhrhammer N, et al: Significant association between IL23R and IL17F polymorphisms and clinical features of colorectal cancer.Immunol Lett 2014, 158:189-194.

29. Zhang S, Wang X: The IL-17A rs2275913 polymorphism is associated with colorectal cancer risk.J Int Med Res 2020, 48:300060520979117.

30. Chaimaa Moundira, Farid Chehabb, Nezha Senhajia, Rachid Boufettalb, Kaoutar Idouza, Driss Erguibib, Sellama Nadif: Association of the IL-17A rs2275913 and MIF rs755622 polymorphisms with the risk of gastric and colorectal cancer. Meta Gene 2019, (22)100605.

31. LiBingsheng, XuAngao, GanAihua, ZhangXiaohui, HuangWenfeng, YuZhonggui, ChenXiaolong: Application of high resolution melting assay to explore the correlation between the single nucleotide polymorphisms of IL-23/IL-17 gene and colorectal cancer. Journal of New Medicine 2016, 47(10)

32. Straus DS: TNFalpha and IL-17 cooperatively stimulate glucose metabolism and growth factor production in human colorectal cancer cells.Mol Cancer 2013, 12:78.

33. Ren H, Wang Z, Zhang S, Ma H, Wang Y, Jia L, Li Y: IL-17A Promotes the Migration and Invasiveness of Colorectal Cancer Cells Through NF-kappaBMediated MMP Expression.Oncol Res 2016, 23:249-256.

34. Liu J, Duan Y, Cheng X, Chen X, Xie W, Long H, Lin Z, Zhu B: IL-17 is associated with poor prognosis and promotes angiogenesis via stimulating VEGF production of cancer cells in colorectal carcinoma.Biochem Biophys Res Commun 2011, 407:348-354.

35. Chung AS, Wu X, Zhuang G, Ngu H, Kasman I, Zhang J, Vernes JM, Jiang Z, Meng YG, Peale FV, et al: An interleukin-17-mediated paracrine network promotes tumor resistance to anti-angiogenic therapy.Nat Med 2013, 19:1114-1123.

36. Sui G, Qiu Y, Yu H, Kong Q, Zhen B: Interleukin-17 promotes the development of cisplatin resistance in colorectal cancer.Oncol Lett 2019, 17:944-950.

37. Sarkar S, Cooney LA, Fox DA: The role of T helper type 17 cells in inflammatory arthritis. Clin Exp Immuno/ 2010, 159:225-237.

38. Ruiz de Morales JMG, Puig L, Dauden E, Canete JD, Pablos JL, Martin AO, Juanatey CG, Adan A, Montalban X, Borruel N, et al: Critical role of interleukin (IL)-17 in inflammatory and immune disorders: An updated review of the evidence focusing in controversies.Autoimmun Rev 2020, 19:102429.

39. Liu J, Xu Q, Yuan Q, Wang Z, Xing C, Yuan Y: Association of IL-17A and IL-17F polymorphisms with gastric cancer risk in Asians: a meta-analysis. Hum Immunol 2015, 76:6-12. 
40. Dai ZM, Zhang TS, Lin S, Zhang WG, Liu J, Cao XM, Li HB, Wang M, Liu XH, Liu K, et al: Role of IL-17A rs2275913 and IL-17F rs763780 polymorphisms in risk of cancer development: an updated meta-analysis.Sci Rep 2016, 6:20439.

41. Elshazli RM, Salman DO, Kamel MM, Toraih EA, Fawzy MS: Genetic polymorphisms of IL-17A rs2275913, rs3748067 and IL-17F rs763780 in gastric cancer risk: evidence from 8124 cases and 9873 controls.Mol Biol Rep 2018, 45:1421-1444.

42. Feng C, Li P, Zhang F, Chen H, Yu P: A Meta-Analysis of the Association Between the VEGF +936C>T Gene Polymorphism and Digestive System Cancer Susceptibility.Genet Test Mol Biomarkers 2020, 24:732-744.

\section{Tables}

Table 1. The criteria list of quality score for included studies

\begin{tabular}{|l|l|}
\hline Criterion & Score \\
\hline Representativeness of cases & 3 \\
\hline Selected from population or cancer registry & 2 \\
\hline Selected from hospital & 1 \\
\hline Selected from pathology archives, but without description & 0 \\
\hline Not described & \\
\hline Source of controls & 3 \\
\hline Population-based & 2 \\
\hline Blood donors or volunteers & 1 \\
\hline Hospital-based (cancer-free patients) & 0 \\
\hline Not described & 3 \\
\hline Case-control match & 3 \\
\hline Matched by age and gender & 0 \\
\hline Not matched by age and gender & 3 \\
\hline Specimens used for determining genotypes & 3 \\
\hline White blood cells or normal tissues & 0 \\
\hline Tumor tissues or exfoliated cells of tissue & 3 \\
\hline Hardy-Weinberg equilibrium (HWE) & 3 \\
\hline Hardy-Weinberg equilibrium in control subjects & 3 \\
\hline Hardy-Weinberg disequilibrium in control subjects & 3 \\
\hline Total sample size & 3 \\
\hline$>1000$ & 3 \\
\hline$>500$ and <1000 & 3 \\
\hline$>200$ and <500 & 3 \\
\hline$<200$ & 3 \\
\hline
\end{tabular}

Table 2. Basic characteristics of included studies for this meta-analysis. 
IL-17A rs2275913

\begin{tabular}{|c|c|c|c|c|c|c|c|c|c|c|c|}
\hline \multirow{2}{*}{$\begin{array}{l}\text { Study } \\
\text { author }\end{array}$} & \multirow{2}{*}{$\begin{array}{l}\text { Study } \\
\text { year }\end{array}$} & \multirow[t]{2}{*}{ Country } & \multirow[t]{2}{*}{ Ethnicity } & \multirow{2}{*}{$\begin{array}{l}\text { Cancer } \\
\text { type }\end{array}$} & \multirow[t]{2}{*}{ Design } & \multirow{2}{*}{$\begin{array}{l}\text { Source } \\
\text { of } \\
\text { controls }\end{array}$} & \multirow{2}{*}{$\begin{array}{l}\text { Genotyping } \\
\text { method }\end{array}$} & \multirow{2}{*}{$\begin{array}{l}\text { Matching } \\
\text { criteria }\end{array}$} & \multicolumn{3}{|l|}{ Cases } \\
\hline & & & & & & & & & $\mathrm{AA}$ & $A G$ & GG \\
\hline Omrane & 2014 & Tunisia & Caucasian & $\begin{array}{l}\text { colorectal } \\
\text { cancer }\end{array}$ & $\begin{array}{l}\text { Retrospective } \\
\text { study }\end{array}$ & $\mathrm{HB}$ & PCR-RFLP & $\begin{array}{l}\text { Not } \\
\text { mentioned }\end{array}$ & $3(2.9 \%)$ & $51(50.0 \%)$ & $48(4 ;$ \\
\hline Nemati & 2015 & Iran & Caucasian & $\begin{array}{l}\text { colorectal } \\
\text { cancer }\end{array}$ & $\begin{array}{l}\text { Retrospective } \\
\text { study }\end{array}$ & PB & PCR-RFLP & $\begin{array}{l}\text { Age, Sex, } \\
\text { Ethnic, } \\
\text { Geographic } \\
\text { origin }\end{array}$ & $82(27.0 \%)$ & $100(32.9 \%)$ & $122(4$ \\
\hline Samiei & 2018 & Malaysia & Asian & $\begin{array}{l}\text { colorectal } \\
\text { cancer }\end{array}$ & $\begin{array}{l}\text { Retrospective } \\
\text { study }\end{array}$ & PB & PCR-RFLP & $\begin{array}{l}\text { Not } \\
\text { mentioned }\end{array}$ & $27(38.6 \%)$ & $33(47.1 \%)$ & $10(1 /$ \\
\hline $\begin{array}{l}\text { Al } \\
\text { Obeed }\end{array}$ & 2018 & $\begin{array}{l}\text { Saudi } \\
\text { Arabia }\end{array}$ & Caucasian & $\begin{array}{l}\text { colorectal } \\
\text { cancer }\end{array}$ & $\begin{array}{l}\text { Retrospective } \\
\text { study }\end{array}$ & $\mathrm{PB}$ & qRT-PCR & $\begin{array}{l}\text { Gender, } \\
\text { Age }\end{array}$ & $17(14.5 \%)$ & $40(34.2 \%)$ & $60\left(5^{1}\right.$ \\
\hline Bedoui & 2018 & Tunisia & Caucasian & $\begin{array}{l}\text { colorectal } \\
\text { cancer }\end{array}$ & $\begin{array}{l}\text { Retrospective } \\
\text { study }\end{array}$ & PB & TaqMan & $\begin{array}{l}\text { Ethnic } \\
\text { origin }\end{array}$ & $14(4.8 \%)$ & $79(27.1 \%)$ & $199(\epsilon$ \\
\hline Feng & 2019 & China & Asian & $\begin{array}{l}\text { colorectal } \\
\text { cancer }\end{array}$ & $\begin{array}{l}\text { Retrospective } \\
\text { study }\end{array}$ & PB & PCR-RFLP & Sex, age & $37(10.5 \%)$ & $154(43.9 \%)$ & $160(4$ \\
\hline Moundir & 2019 & Morocco & Caucasian & $\begin{array}{l}\text { colorectal } \\
\text { cancer }\end{array}$ & $\begin{array}{l}\text { Retrospective } \\
\text { study }\end{array}$ & $\mathrm{HB}$ & TaqMan & $\begin{array}{l}\text { Not } \\
\text { mentioned }\end{array}$ & $41(58.6 \%)$ & $22(31.4 \%)$ & $7(10$. \\
\hline Zhang & 2020 & China & Asian & $\begin{array}{l}\text { colorectal } \\
\text { cancer }\end{array}$ & $\begin{array}{l}\text { Retrospective } \\
\text { study }\end{array}$ & PB & PCR-RFLP & $\begin{array}{l}\text { Gender, } \\
\text { Age }\end{array}$ & $41(19.7 \%)$ & $110(52.9 \%)$ & $57(2 ;$ \\
\hline \multicolumn{12}{|c|}{ IL-17F rs763780 } \\
\hline \multirow{2}{*}{$\begin{array}{l}\text { Study } \\
\text { author }\end{array}$} & \multirow{2}{*}{$\begin{array}{l}\text { Study } \\
\text { year }\end{array}$} & \multirow{2}{*}{$\begin{array}{l}\text { Geographic } \\
\text { area }\end{array}$} & \multirow[t]{2}{*}{ Ethnicity } & \multirow{2}{*}{$\begin{array}{l}\text { Cancer } \\
\text { type }\end{array}$} & \multirow[t]{2}{*}{ Design } & \multirow{2}{*}{$\begin{array}{l}\text { Source } \\
\text { of } \\
\text { controls }\end{array}$} & \multirow{2}{*}{$\begin{array}{l}\text { Genotyping } \\
\text { method }\end{array}$} & \multirow{2}{*}{$\begin{array}{l}\text { Matching } \\
\text { criteria }\end{array}$} & \multicolumn{3}{|c|}{ Cases } \\
\hline & & & & & & & & & $\mathrm{CC}$ & CT & $\mathrm{TT}$ \\
\hline Omrane & 2014 & Tunisia & Caucasian & $\begin{array}{l}\text { colorectal } \\
\text { cancer }\end{array}$ & $\begin{array}{l}\text { Retrospective } \\
\text { study }\end{array}$ & $\mathrm{HB}$ & PCR-RFLP & $\begin{array}{l}\text { Not } \\
\text { mentioned }\end{array}$ & $1(0.7 \%)$ & $38(27.8 \%)$ & $98(71$ \\
\hline Nemati & 2015 & Iran & Caucasian & $\begin{array}{l}\text { colorectal } \\
\text { cancer }\end{array}$ & $\begin{array}{l}\text { Retrospective } \\
\text { study }\end{array}$ & PB & PCR-RFLP & $\begin{array}{l}\text { Age, Sex, } \\
\text { Ethnic, } \\
\text { Geographic } \\
\text { origin }\end{array}$ & $337(93.6 \%)$ & $0(0.0 \%)$ & $23(6$. \\
\hline $\mathrm{Li}$ & 2016 & China & Asian & $\begin{array}{l}\text { colorectal } \\
\text { cancer }\end{array}$ & $\begin{array}{l}\text { Retrospective } \\
\text { study }\end{array}$ & PB & PCR-HRM & Sex, Age & $0(0.0 \%)$ & $13(26.0 \%)$ & $37(7 /$ \\
\hline Samiei & 2018 & Malaysia & Asian & $\begin{array}{l}\text { colorectal } \\
\text { cancer }\end{array}$ & $\begin{array}{l}\text { Retrospective } \\
\text { study }\end{array}$ & PB & PCR-RFLP & $\begin{array}{l}\text { Not } \\
\text { mentioned }\end{array}$ & $5(7.2 \%)$ & $25(35.7 \%)$ & $40(5 ;$ \\
\hline $\begin{array}{l}\text { Al } \\
\text { Obeed }\end{array}$ & 2018 & $\begin{array}{l}\text { Saudi } \\
\text { Arabia }\end{array}$ & Caucasian & $\begin{array}{l}\text { colorectal } \\
\text { cancer }\end{array}$ & $\begin{array}{l}\text { Retrospective } \\
\text { study }\end{array}$ & PB & qRT-PCR & $\begin{array}{l}\text { Gender, } \\
\text { Age }\end{array}$ & $110(94.0 \%)$ & $7(6.0 \%)$ & $0(0.0$ \\
\hline Feng & 2019 & China & Asian & $\begin{array}{l}\text { colorectal } \\
\text { cancer }\end{array}$ & $\begin{array}{l}\text { Retrospective } \\
\text { study }\end{array}$ & PB & PCR-RFLP & Sex, Age & $10(2.8 \%)$ & $100(28.5 \%)$ & $241(\epsilon$ \\
\hline
\end{tabular}

Table 3. Pooled ORs and 95\% Cls of this meta-analysis for the effect of IL-17A rs2275913 and IL-17F rs763780 polymorphism on colorectal cancer. 


\begin{tabular}{|c|c|c|c|c|c|c|c|c|c|c|c|c|}
\hline & \multicolumn{4}{|l|}{ Allele model } & \multicolumn{4}{|l|}{ Dominant model } & \multicolumn{4}{|l|}{ Recessive model } \\
\hline & $\mathrm{OR}(95 \% \mathrm{Cl})$ & $\mathrm{P}$ & $\mathrm{P}_{\mathrm{h}}$ & $\mathrm{I}^{2}(\%)$ & $\mathrm{OR}(95 \% \mathrm{Cl})$ & $\mathrm{P}$ & $P_{h}$ & $\mathrm{I}^{2}(\%)$ & $\mathrm{OR}(95 \% \mathrm{Cl})$ & $\mathrm{P}$ & $P_{h}$ & $\mathrm{I}^{2}(\%)$ \\
\hline $\begin{array}{l}\text { IL-17A } \\
\text { rs2275913 } \\
\text { (G197A) }\end{array}$ & Avs. $\mathbf{G}$ & & & & $A A$ / AG vs. GG & & & & AA vs. GG /AG & & & \\
\hline Total & $1.59(1.34,1.89) *$ & $<0.001$ & 0.035 & 53.5 & $1.75(1.36,2.25) *$ & $<0.001$ & 0.018 & 58.5 & $1.74(1.41,2.15) *$ & $<0.001$ & 0.437 & 0 \\
\hline \multicolumn{13}{|l|}{ Ethnicity } \\
\hline Asian & $1.52(1.16,2.01) *$ & 0.003 & 0.067 & 63.0 & $1.62(1.18,2.23)^{*}$ & 0.003 & 0.186 & 40.6 & $1.72(1.26,2.34)^{*}$ & 0.001 & 0.131 & 50.8 \\
\hline Caucasian & $1.67(1.30,2.14)^{*}$ & $<0.001$ & 0.058 & 56.2 & $1.88(1.26,2.81)^{\star}$ & 0.002 & 0.009 & 70.3 & $1.76(1.32,2.36)^{*}$ & $<0.001$ & 0.585 & 0 \\
\hline \multicolumn{13}{|l|}{$\begin{array}{l}\text { Genotyping } \\
\text { Method }\end{array}$} \\
\hline PCR-RFLP & $1.47(1.24,1.74) *$ & $<0.001$ & 0.156 & 39.8 & $1.61(1.23,2.11)^{*}$ & 0.001 & 0.075 & 52.9 & $1.68(1.33,2.14)^{\star}$ & $<0.001$ & 0.219 & 30.4 \\
\hline qRT-PCR & $2.04(1.30,3.20) *$ & 0.002 & - & - & $2.22(1.27,3.88) *$ & 0.005 & - & - & $2.26(0.90,5.69)^{*}$ & 0.084 & - & - \\
\hline TaqMan & $1.84(0.90,3.76)$ & 0.092 & 0.017 & 82.5 & $2.42(0.68,8.68)$ & 0.174 & 0.01 & 85.0 & $1.88(1.10,3.19)^{*}$ & 0.02 & 0.4 & 0 \\
\hline \multicolumn{13}{|l|}{$\begin{array}{l}\text { Source of } \\
\text { Controls }\end{array}$} \\
\hline PB & $1.47(1.25,1.72) *$ & $<0.001$ & 0.138 & 40.1 & $1.50(1.23,1.83) *$ & $<0.001$ & 0.197 & 31.8 & $1.74(1.39,2.18)^{*}$ & $<0.001$ & 0.465 & 0 \\
\hline $\mathrm{HB}$ & $2.15(1.41,3.29) *$ & $<0.001$ & 0.2 & 39.0 & $3.15(1.59,6.21) *$ & 0.001 & 0.182 & 43.9 & $1.77(0.98,3.21)$ & 0.06 & 0.129 & 56.5 \\
\hline $\begin{array}{l}\text { IL-17F } \\
\text { rs763780 } \\
\text { (T7488C) }\end{array}$ & Cvs. T & & & & CC/ CT vs. TT & & & & CC vs. TT / CT & & & \\
\hline Total & $0.94(0.63,1.41)$ & 0.776 & 0.009 & 67.5 & $0.96(0.64,1.44)$ & 0.845 & 0.058 & 56.2 & $0.71(0.45,1.12)$ & 0.141 & 0.18 & 36.2 \\
\hline \multicolumn{13}{|l|}{ Ethnicity } \\
\hline Asian & $1.21(0.73,2.01)$ & 0.466 & 0.067 & 62.9 & $1.17(0.72,1.89)$ & 0.527 & 0.142 & 48.8 & $1.07(0.53,2.18)$ & 0.844 & 0.076 & 68.2 \\
\hline Caucasian & $0.71(0.36,1.36)$ & 0.317 & 0.043 & 68.2 & $0.67(0.27,1.63)$ & 0.376 & 0.055 & 72.8 & $0.54(0.30,0.98) *$ & 0.042 & 0.421 & 0 \\
\hline \multicolumn{13}{|l|}{$\begin{array}{l}\text { Genotyping } \\
\text { Method }\end{array}$} \\
\hline PCR-RFLP & $0.89(0.54,1.46)$ & 0.649 & 0.002 & 79.3 & $0.91(0.58,1.43)$ & 0.683 & 0.04 & 64.0 & $0.67(0.41,1.09)$ & 0.109 & 0.125 & 47.8 \\
\hline qRT-PCR & $1.00(0.33,3.03)$ & 0.996 & - & - & - & - & - & - & $1.00(0.33,3.09)$ & 0.996 & - & - \\
\hline TaqMan & $1.34(0.56,3.23)$ & 0.507 & - & - & $1.41(0.55,3.59)$ & 0.477 & - & - & - & - & - & - \\
\hline \multicolumn{13}{|l|}{$\begin{array}{l}\text { Source of } \\
\text { Controls }\end{array}$} \\
\hline PB & $0,94(0.57,1.55)$ & 0.804 & 0.004 & 73.6 & $0.95(0.56,1.63)$ & 0.854 & 0.029 & 66.7 & $0.71(0.45,1.12)$ & 0.146 & 0.099 & 52.1 \\
\hline $\mathrm{HB}$ & $1.01(0.60,1.69)$ & 0.976 & - & - & $1.02(0.58,1.81)$ & 0.937 & - & - & $0.73(0.04,11.78)$ & 0.823 & - & - \\
\hline
\end{tabular}

\section{Figures}




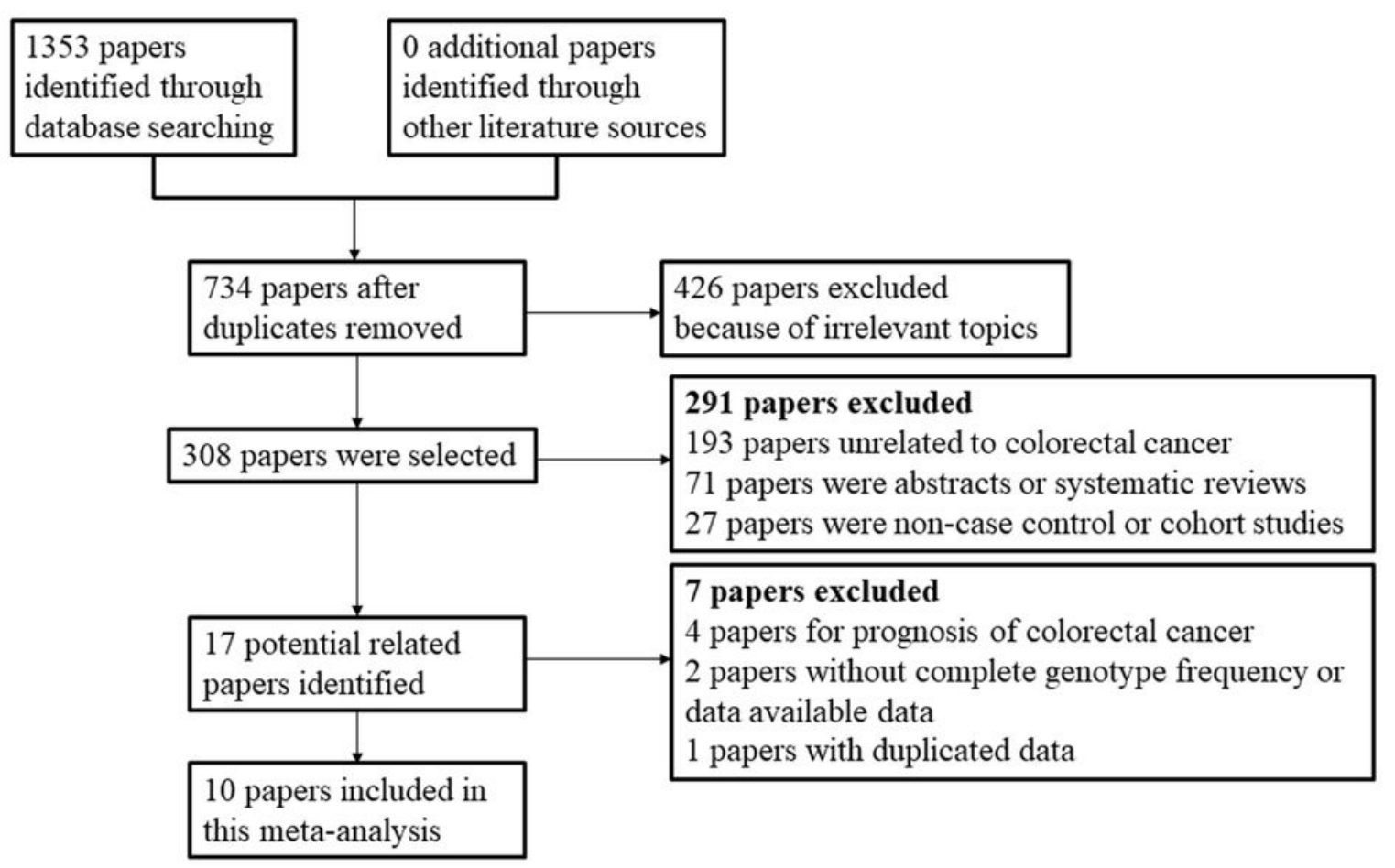

Figure 1

Flow diagram for the literatures included in this present meta-analysis

A

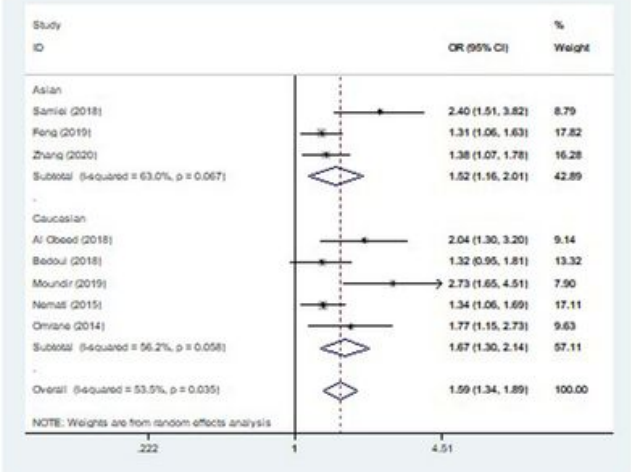

D

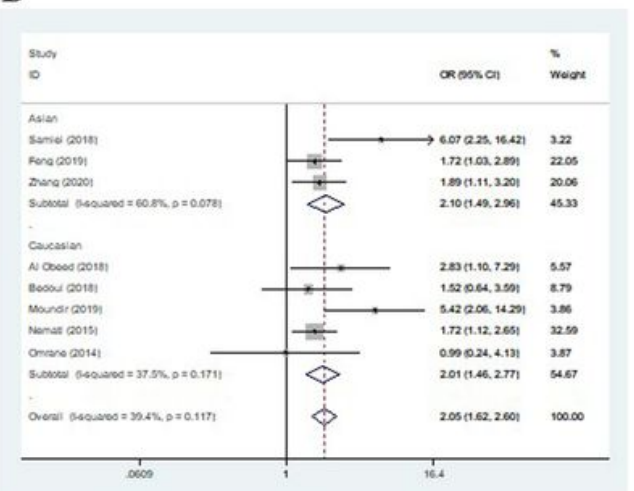

B

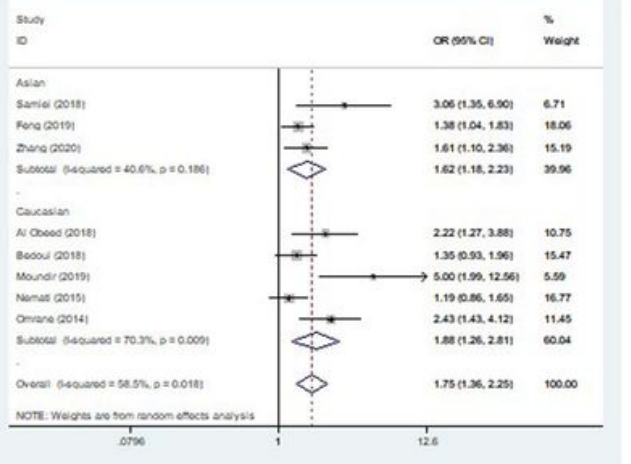

E

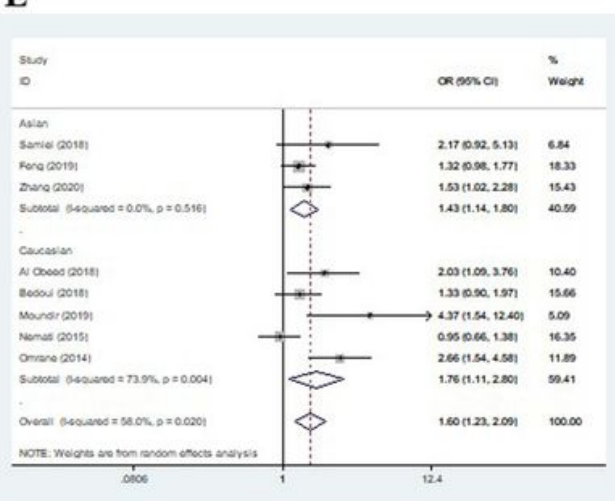

C

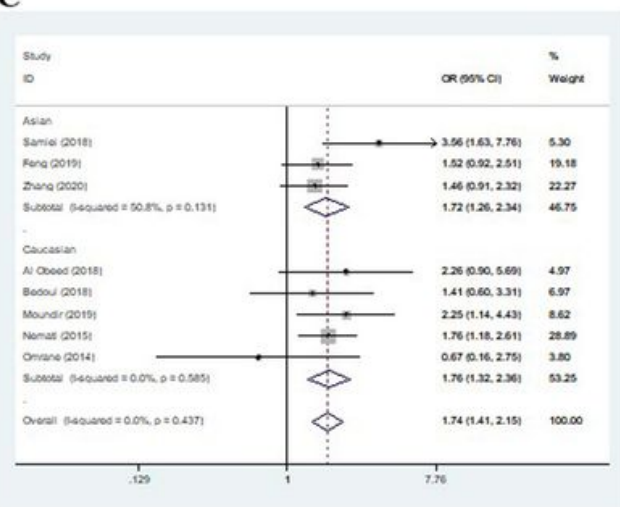

Figure 2 
Forest plots of all the genetic models for the associations between IL-17A rs2275913 polymorphism and colorectal cancer. A. allelic model (A vs. G). B. dominant model (AA/AG vs. GG). C. recessive model (AA vs. GG/AG). D. homozygous model (AA vs. GG). E. heterozygous model (AG vs. GG). The studyspecific ORs are represented as squares. The size of the square indicates the weight of each study. The horizontal lines represent $95 \%$ Cls. Diamonds show the overall estimate or pooled ORs in subgroups with their corresponding 95\% Cis.

A

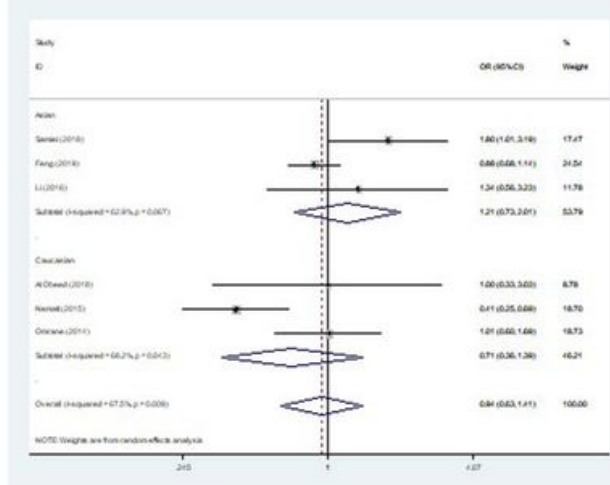

D

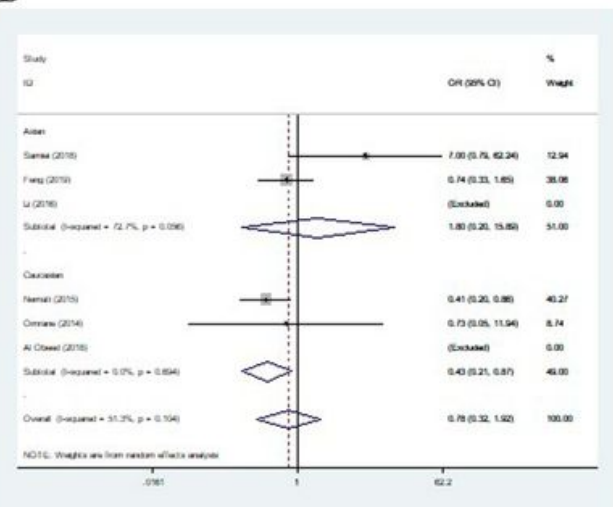

B

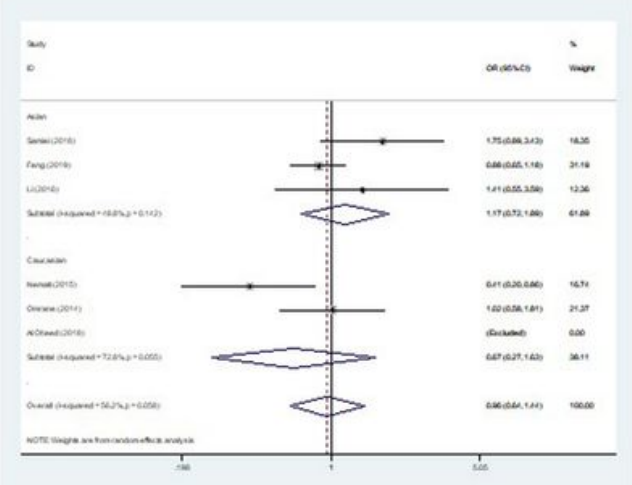

$\mathbf{E}$

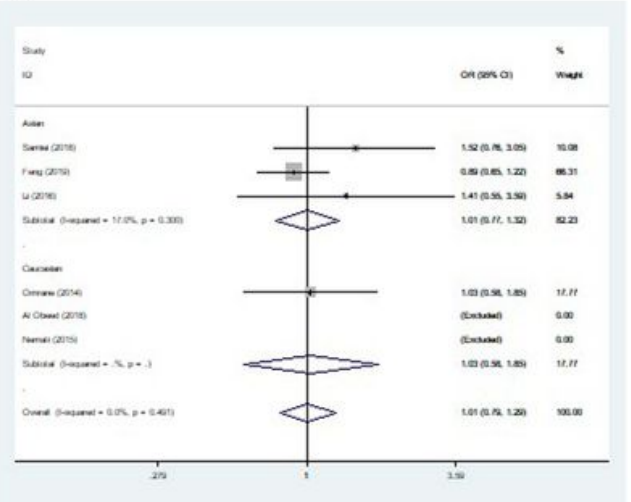

C

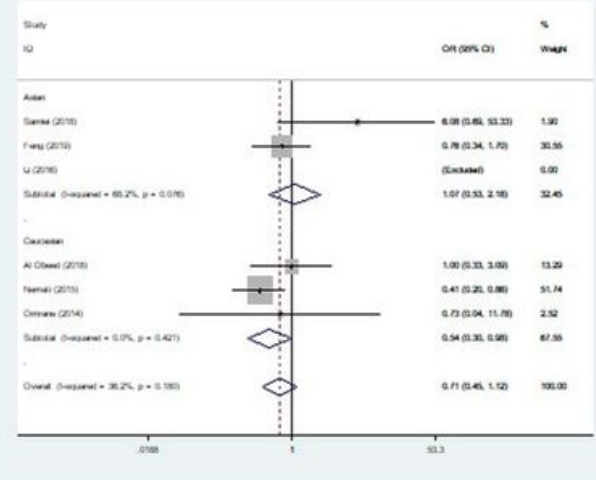

Figure 3

Forest plots of all the genetic models for the associations between IL-17F rs763780 polymorphism and colorectal cancer. A. allelic model (C vs. T). B. dominant model (CC/CT vs. TT). C. recessive model (CC vs. TT/CT). D. homozygous model (CC vs. TT). E. heterozygous model (CT vs. TT). The study-specific ORs are represented as squares. The size of the square indicates the weight of each study. The horizontal lines represent $95 \%$ Cls. Diamonds show the overall estimate or pooled ORs in subgroups with their corresponding $95 \%$ Cis. 


\section{A}

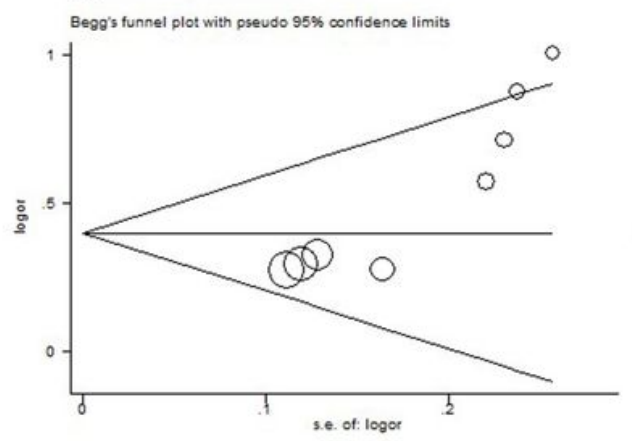

\section{D}

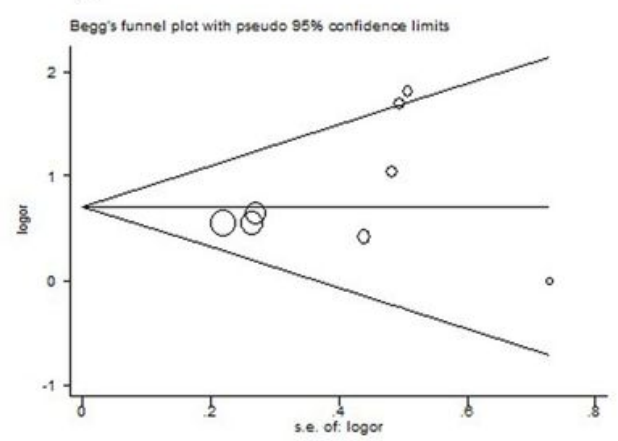

\section{B}

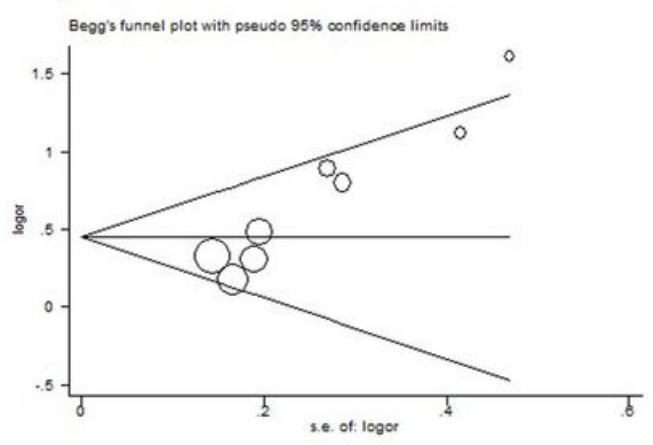

E

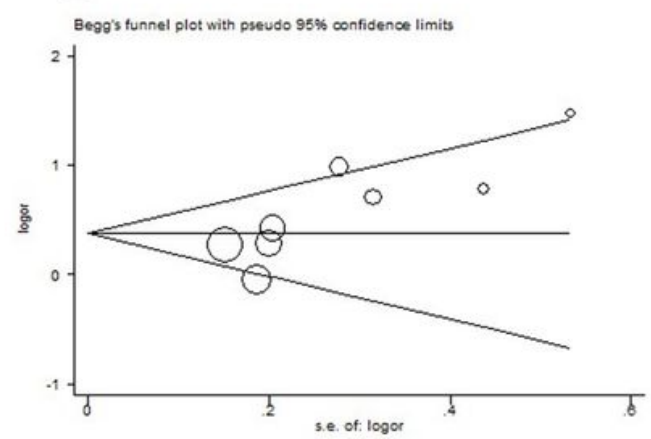

C

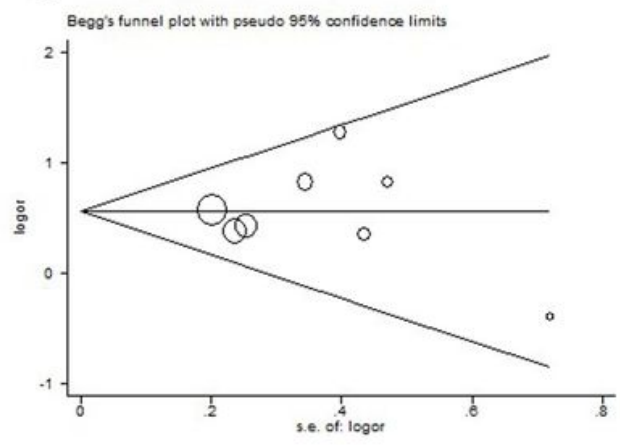

\section{Figure 4}

Funnel plots performed to detect the publication bias of included studies regarding to IL-17A rs2275913 polymorphism. A. allelic model (A vs. G). B. dominant model (AA/AG vs. GG). C. recessive model (AA vs. GG/AG). D. homozygous model (AA vs. GG). E. heterozygous model (AG vs. GG). Each cycle represents an individual case-control study.

A

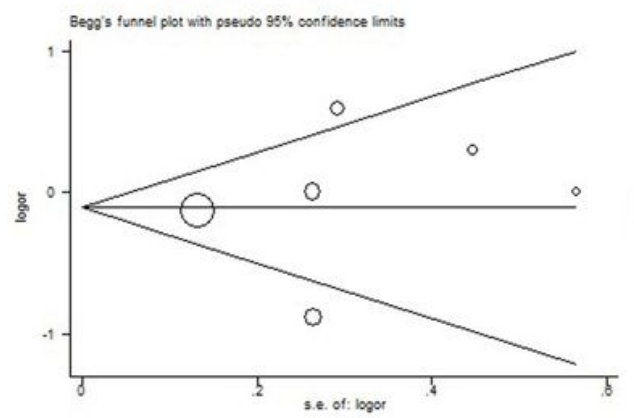

D

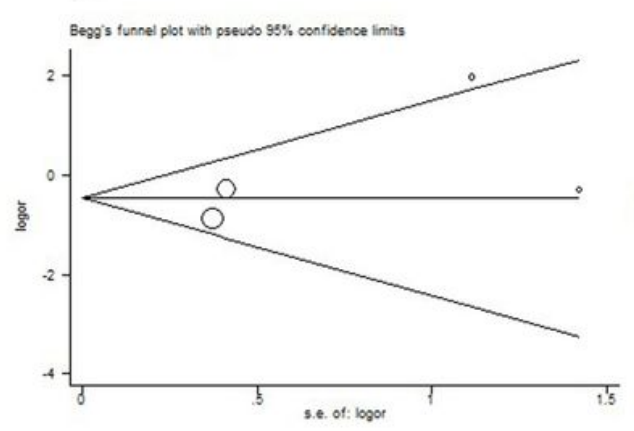

B

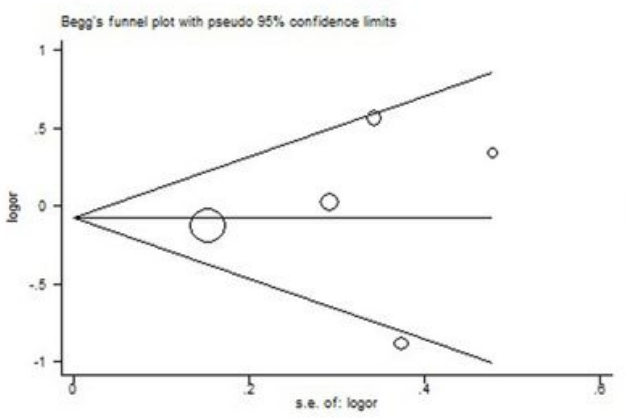

E

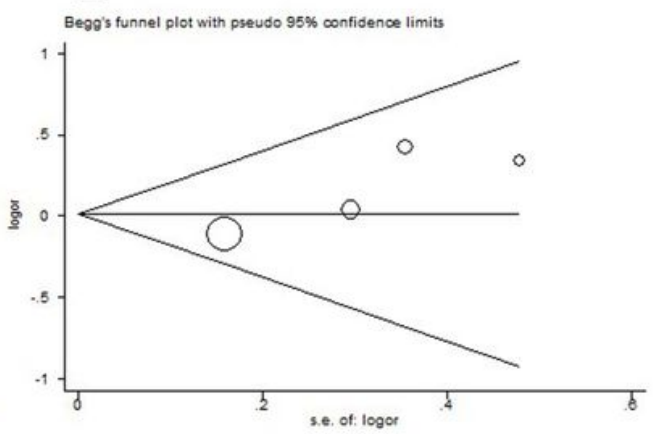

C

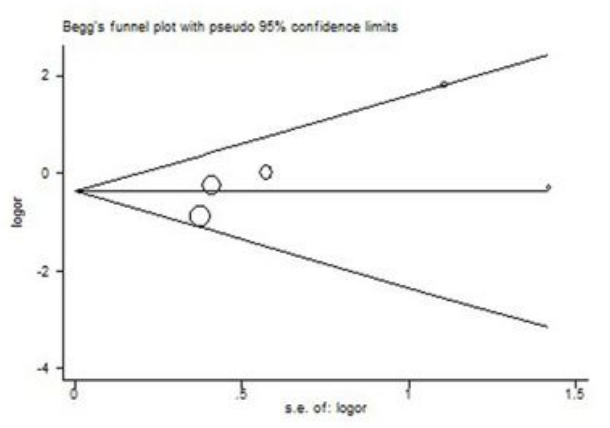

Figure 5 
Funnel plots performed to detect the publication bias of included studies regarding to IL-17F rs763780 polymorphism. A. allelic model (C vs. T). B. dominant model (CC/CT vs. TT). C. recessive model (CC vs. TT/CT). D. homozygous model (CC vs. TT). E. heterozygous model (CT vs. TT). Each cycle represents an individual case-control study. 